Available online on 15.05.2017 at http://jddtonline.info
C 2011-17, publisher and licensee JDDT, This is an Open Access article which permits unrestricted
noncommercial use, provided the original work is properly cited

Research Article

\title{
WATER ABSORPTION, XRD AND FTIR ANALYSIS OF PBS- STARCH BLENDED HALLOYSITE COMPOSITES
}

\author{
Dash BK \\ Micro and Nano Materials Laboratory, Department of Chemistry, Institute of Technical Education and Research, Siksha'O'Anusandhan \\ University, Khandagiri Square, Bhubaneswar, Odisha, India
}

\begin{abstract}
Poly (butylene succinct) (PBS)/starch/halloysite nanotubes(HNT) composite was fabricated through solution casting using deionised water. The effect of HNT on the water absorption behavior of the composites has been studied and found to be decreasing with the increase in loading of HNT. The characterizations of the composites were carried out by the Fourier Transform Infrared spectroscopy (FTIR), X-ray diffraction (XRD). XRD and FTIR results indicated halloysite was successfully incorporated to PBS-Starch blend through solution casting method. XRD showed that the basal spacing of PBS-Starch increased because of the presence of halloysite. The UV Study shows the good shielding property of the blend Nanocomposites. From the Water absorption test, it is found that the water absorption tendency of the hybrid composites decreases regularly.
\end{abstract}

Keywords: HNT, XRD, water absorption, composites.

Article Info: Received 28 March, 2017; Review Completed 27 April, 2017; Accepted 27 April, 2017; Available online May 15, 2017

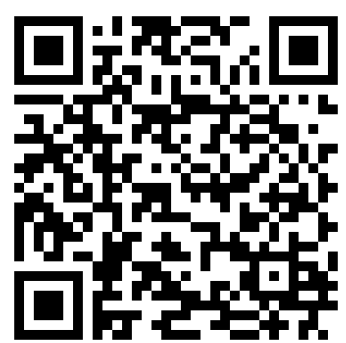

Cite this article as:

Dash BK, Water absorption, XRD and FTIR analysis of PBS-Starch blended Halloysite composites, Journal of Drug Delivery and Therapeutics. 2017; 7(3):98-101

DOI: http://dx.doi.org/10.22270/jddt.v7i3.1440

*Address for Correspondence

Bikash Kumar Dash, Micro and Nano Materials Laboratory, Department of Chemistry, Institute of Technical Education and Research, Siksha'O'Anusandhan University, Khandagiri Square, Bhubaneswar, Odisha, India

*E-mail: bksh.chem@gmail.com, Phone no.91-674-2351880

\section{INTRODUCTION}

The polymeric materials are generally nonbiodegradable, thus widely used of these polymers for disposable applications significantly damaging the earth's ecosystem. The environmental effect of polymer plastic wastes brings global concern to a worrying status. Considerable attention has been paid to biodegradation polymers, mainly owing to increase interest for preservation of environment. Many efforts have been made to solve problems generated by plastic waste, particularly by one-time use disposable commodity materials. Most of the research attention was focused on the replacement of petro-based plastics by biodegradable material with similar mechanical properties.
Biodegradable polymers have been considered as most promising materials for this purpose.

One of the methods to improve these biodegradable polymers is to develop nanocomposites using these materials. Nanocomposites constitute one of the most developed areas of nanotechnology. These materials being refer to composite components with nanoscale dimensions. Commonly, such fillers have at least one dimension in nanometer range and typically 1 to $20 \mathrm{~nm}$ (Komarneni, 1992).The poly(butylene succinate) reinforced with halloysite nanotubes showed that the addition of HNT decreased the decomposition temperature and activation energy accelerated the 
thermal degradation. It was demonstrated by the X-ray diffractometry spectra that the incorporation of HNT did not affect the crystal form of $\mathrm{PBS}^{1}$. The effect of Halloysite on plasticized starch for the preparation of porous nanocomposites suitable for biomedical applications has been found in the literature ${ }^{2}$. The study shows that the introduction of halloysite has double benefits: (1) these act both as a nucleating agent increasing the porosity and (2) also as a barrier agent increasing the proportion of small cells. Studies also have been carried out on the preparation and properties of novel melt-blended halloysite nanotubes/wheat starch Nanocomposites $^{3}$ which shows that addition of halloysite nanotubes slightly enhances the thermal stability of starch as well as lead to significantly higher Young's modulus than unmodified halloysites. In literature ${ }^{4}$, casting method was used to prepare potato starch based bio-nanocomposite films with halloysite nanoclay as the reinforcing materials which shows that after the addition of halloysite nanoclay, there is improvement in the barrier and mechanical properties of potato starch films and the bionanocomposites have high potential to be used for food packaging purposes.

\section{MATERIALS AND METHODS}

\section{Materials}

Commercial Poly Butylene Succinate(PBS) and Halloysite was purchased from Sigma Aldrich ,India. Starch was purchased from MERCK (India) Ltd., Mumbai, India. Double distilled water was used as a solvent.

\section{Method}

Preparation of PBS/Starch/Halloysite composites

PBS was dissolved in distilled water under vigorous stirring along with starch with the help of magnetic stirrer, while Halloysite dispersions were obtained by dispersing Halloysite in distilled water with the help of ultrasonication. The mixtures of PBS Starch solutions and Halloysite dispersions were stirred for 3 hour and then it was casted over a Teflon tray. After that, the solvents were evaporated by air drying followed by vacuum drying. Loading of the fillers are varied as 10 , 20, 30 and $40 \mathrm{phr}$.

\section{Characterization methods}

\section{XRD Study}

The powder X-ray diffraction (XRD) analysis was performed using a powder diffractometer with $\mathrm{Cu}$ target and $\mathrm{K} \alpha(\lambda=0.154056 \mathrm{~nm})$ at $40 \mathrm{kV}$ with a slow scan of 0.3 degree/s in $2 \theta$ range $10-50$ degree at room temperature. The crystallite size of the nanocomposite was determined from the XRD study by the Scherrer Equation.

$\mathrm{t}=0.9 \lambda / \mathrm{B} \cdot \cos \theta$

Where, $\mathrm{t}=$ thickness of crystallite, $\lambda=\mathrm{x}$-ray wavelength,

$\mathrm{B}=(2 \theta$ High $)-(2 \theta$ Low $)$

\section{Water absoption study (ASTMD570 method)}

In Step-1, all the samples have been dried in vaccum oven for 24 hour. In Step-2, the weight (dry) of all the samples has been taken. In Step-3, all the samples are emerged into the beaker containing $100 \mathrm{ml}$ and time is noted. In Step-4, the regular weight of the wettable samples after dry with the paper is taken till the Constant weight to be achieved.

\section{RESULTS AND DISCUSSION}

FTIR Analysis

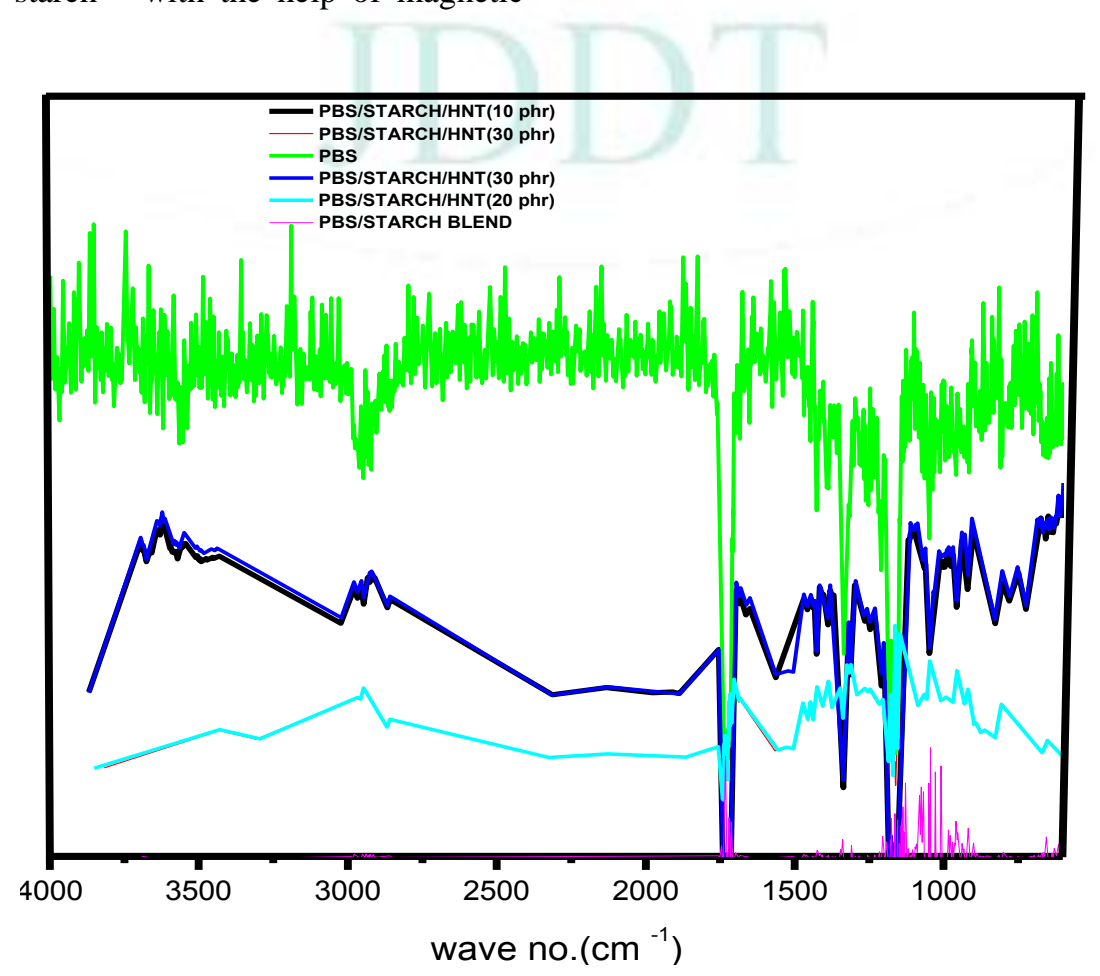

Figure 1: FTIR Analysis of PBS/Starch/Halloysite composites 
The strong absorption band around $912 \mathrm{~cm}^{-1}$ (Al-OH Vibration) and $1032 \mathrm{~cm}^{-1}$ (Si-O Vibration) shows the presence of halloysite in the composites. The Two broad absorption peak $\left(3000 \mathrm{~cm}^{-1}-3900 \mathrm{~cm}^{-1}\right)$ proves the intermolecular hydrogen bonding between the starch and PBS. The streching vibration around the $1736 \mathrm{~cm}^{-1}$ shows the C-O-C linkage in the composites. The band around $3623 \mathrm{~cm}^{-1}$ shows the ' $\mathrm{O}-\mathrm{H}$ ' Streching vibration in the composites.

\section{XRD Study}

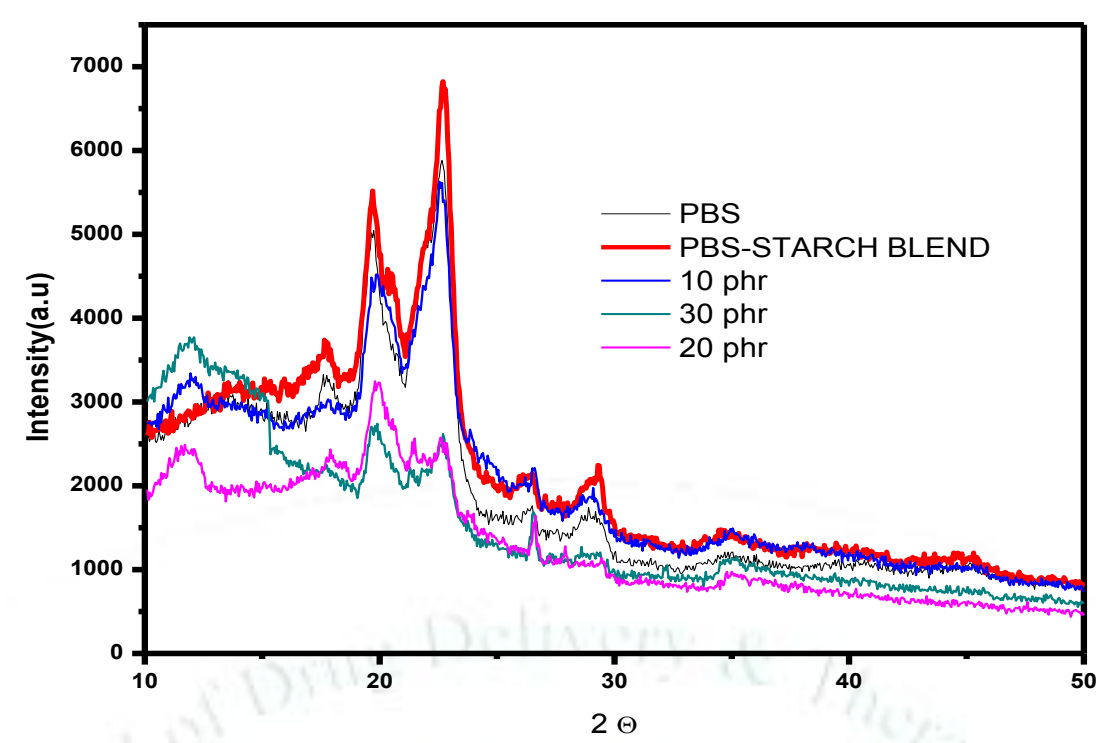

Figure 2: XRD Study of PBS, PBS/Starch blend and PBS/Starch/HNT composites.

It shows the good compatibility between the halloysite and PBS as it is clearly observed since interlayer is increased. Peaks position move to lower angle.
Dispersion of HNT is satisfactory.HNT may act as nucleating agent for PBS and increase its crystallinity.

UV study

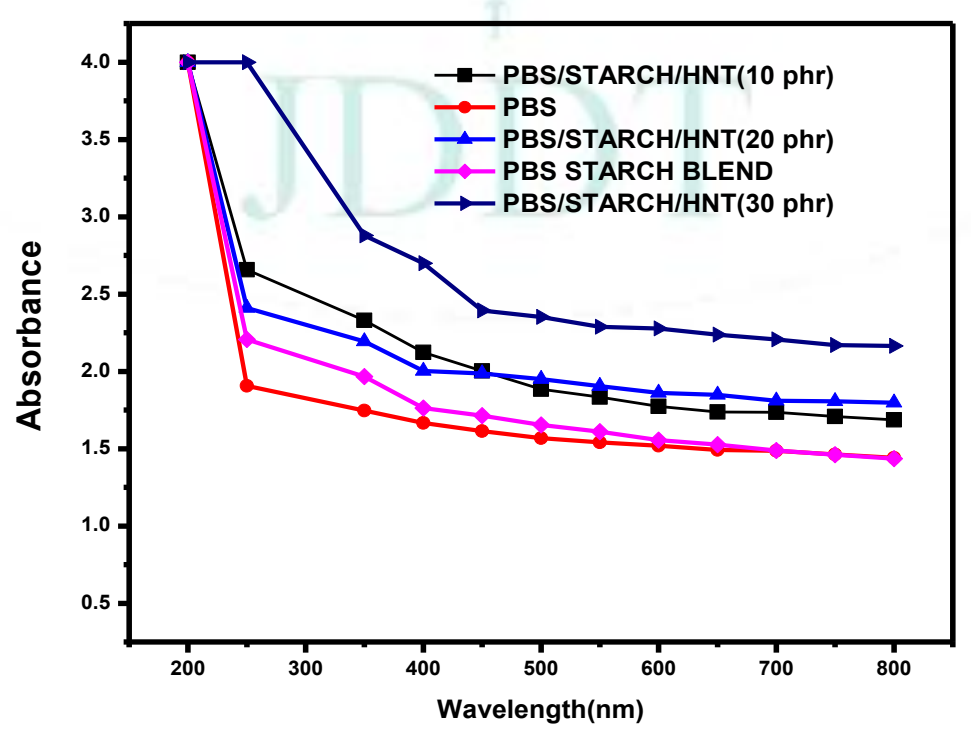

Figure 3: UV study of the PBS, PBS/Starch blend and PBS/Starch/HNT filled composites.

The Fig.3 shows the UV study of the PBS, PBS/Starch blend and PBS/Starch/HNT filled composites. In between 200-300 $\mathrm{nm}$ is considered as the UV region. The hybrid samples are having the good UV absorbing properties than the PBS. This is due to good interaction between the polymer and halloysite material that shields the UV radiation ${ }^{5}$. The absorbance is least for the PBS and the maximum for the $30 \mathrm{phr}$ loading which shows the fair UV shielding tendency of the HNT filled composites. 
Water absorption test

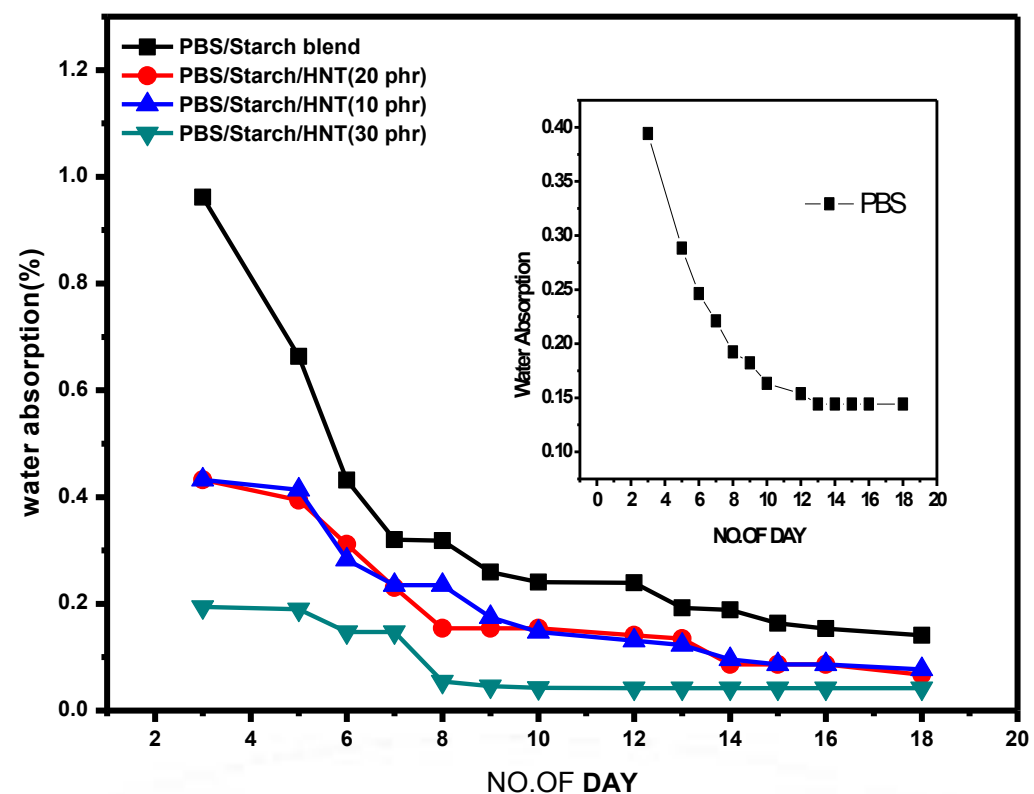

Figure 4: Water absorption of the PBS, PBS/Starch blend and PBS/Starch/HNT filled composites

The Fig. 4 shows the Water absorption of the PBS, PBS/Starch blend and PBS/Starch/HNT filled composites. The water absorption tendency of the hybrid composites decreases regularly. All the halloysite filled nanocomposites show less water absorbing tendency than the PBS itself. More is the HNT content less is the water absorption. The $30 \mathrm{phr}$ loading of HNT shows least tendency for the water absorption in comparison to other loadings. It can be clearly observed from the figure that after 15 days, there is no longer water absorption for all the composites as well as the neat PBS.

\section{REFERENCES}

1. Wu W, Cao X, Luo J, Guangjian H, Zhang Y, Morphology, thermal, and mechanical properties of poly (butylene succinate) reinforced with halloysite nanotubes. Polymer Composites. 2014; 35(5):847-855. DOI: 10.1002/pc.22728

2. Schmitt H, Creton N, Prashantha K, Soulestin J, Lacrampe M, Krawczak P, Preparation and characterization of plasticized starch/halloysite porous nanocomposites possibly suitable for biomedical applications, Journal of Applied Polymer Science. 2015;132(4): DOI: 10.1002/app.41341.

3. Schmitt H, Prashantha K, Soulestin J, Lacrampe MF, Krawczak P, Preparation and properties of novel melt-

\section{CONCLUSION}

Poly (butylene succinate) (PBS)/starch/halloysite nanotubes(HNT) composites were fabricated through solution casting using deionised water as a solvent. The strong absorption band shows the presence of halloysite in the composites. The least tendency for the water absorption for the biuocomposites shows the good incorporation of the halloysite filler in the PBS/Starch blend. The UV shielding tendency of the HNT filled composites increases with the filler loading. The XRD study shows the good compatibility between the halloysite, PBS and starch which reflects in their characteristic property.

blended halloysite nanotubes/wheat starch Nanocomposites Carbohydrate Polymers. 2012; 89(3):920-927.

4. Sadegh-Hassani F, Mohammadi NA, Preparation and characterization of bionanocomposite films based on potato starch/halloysite nanoclay Int J Biol Macromol. 2014; 67:45862. doi: 10.1016/j.ijbiomac.2014.04.009.

5. Christian C, Mohammed H, Vincent VFL, Functionalisation of polybutylene succinate nanocomposites: from structure to reinforcement of UV-absorbing and mechanical properties RSC Advances, 2012; 2:5430-5438. DOI: $10.1039 / \mathrm{c} 2 \mathrm{ra} 20579 \mathrm{c}$ 